\title{
Evaluating the Effect of Monitoring through Telephone (Tele-Monitoring) on Self-Care Behaviors and Readmission of Patients with Heart Failure after Discharge
}

\author{
Reza Negarandeh ${ }^{1}$ Mitra Zolfaghari ${ }^{2} \quad$ Nazli Bashi ${ }^{3}$ \\ ${ }^{1}$ Nursing and Midwifery Care Research Center, School of Nursing and \\ Midwifery, Tehran University of Medical Sciences, Tehran, Iran \\ ${ }^{2}$ Department of E-Learning in Medical Education, Tehran University of \\ Medical Sciences, Virtual School, Tehran, Iran \\ ${ }^{3}$ The Australian E-Health Research Center, Commonwealth Scientific \\ and Industrial Research Organisation, Brisbane, Australia \\ ${ }^{4}$ Department of Nursing \& Emergency Medicine, Dezful University of \\ Medical Sciences, Dezful, Iran
}

Appl Clin Inform 2019;10:261-268.

\author{
Maryam Kiarsi ${ }^{4}$
}

\begin{abstract}
Address for correspondence Maryam Kiarsi, MSc, Department of Nursing \& Emergency Medicine, Dezful University of Medical Sciences, Dezful 6461665145, Iran (e-mail: maryam.kiarsi2013@gmail.com).
\end{abstract}

\section{Abstract}

Keywords

- tele-monitoring

- self-care

- readmission

- heart failure
Background Heart failure is one of the serious cardiovascular diseases, which poses a global pandemic and places a heavy burden on health care systems worldwide. The incidence of this disease in Iran is higher than in other Asian countries. To reduce patients' complications, readmission rates, and health care expenditures, it is necessary to design interventions, which are culturally appropriate and based on community needs.

Methods In 2016, a randomized clinical trial (IRCT2017010731804N1) was initiated to compare tailored tele-monitoring intervention with usual care. In total, 80 patients completed the study after a follow-up period of 8 weeks. The primary end point was heart failure self-care, which was measured using the Iranian version of the European Heart Failure self-care questionnaire. Secondary end points were heart failure related readmission rates. Results The mean scores for self-care behaviors of the two groups showed significant difference at the baseline $(p=0.045)$. The results of the analysis of covariance that was used to control the differences in the pretest scores of self-care behaviors showed that the difference between both groups after the intervention was still significant $(p<0.001)$. The percentage of patients' readmissions in the intervention group (20\%) was less than that in the control group (42.2\%); however, the results were not statistically significant $(p=0 / 066)$.

Conclusion This study showed that tele-monitoring improved self-care behaviors in Iranian patients with heart failure but did not reduce their readmission rates.

\section{Background and Significance}

Heart failure (HF) occurs when the heart muscle becomes very weak and is not able to efficiently pump blood through the body to meet the tissues' needs of oxygen and nutrients. ${ }^{1}$ $\mathrm{HF}$ is mainly caused by cardiovascular disease (CVD) related conditions, which include cardiomyopathy, coronary artery disease (myocardial infarction and ischemia), chronic hyper- tension, arrhythmias, heart valve disease, CVD, and noncardiac causes such as metabolic diseases, chronic anemia, and chemotherapy drugs. ${ }^{1,2}$ The prevalence of this disease is estimated to affect more than 26 million people globally. ${ }^{3}$

Approximately 5.7 million (2.2\%) adults aged $\geq 20$ years in the United States have HF. In contrast to Western countries, there exists a large gap in information relating to HF in Asia. received

October 17, 2018

accepted after revision

February 28, 2019 (c) 2019 Georg Thieme Verlag KG Stuttgart · New York
DOI https://doi.org/

10.1055/s-0039-1685167. ISSN 1869-0327. 
According to the America Heart Association, the current estimate of HF prevalence in this region ranges from 1.26 to $6.7 \% .{ }^{4}$ In Iran, there are few reliable epidemiological statistics available to estimate the incidence/prevalence of CVDs and long-term survival rate of HF. The few studies available in Iran have reported high prevalence as well as high mortality rate, and unfavorable survival rates or high inhospital mortality rates. ${ }^{5}$ According to a recent study in 2014 , HF prevalence was $8 \%$ in Iran. ${ }^{6}$ The global economic burden of HF is estimated to cost US $\$ 108$ billion per year, with US\$65 billion as direct cost and US\$43 billion as indirect cost. ${ }^{7}$

To achieve positive effects on clinical and patientreported outcomes, most programs for management of HF focus on self-management interventions. Hence, the best therapeutic results would be achieved when the patient is actively involved in self-managing his/her condition. ${ }^{8}$ Selfcare includes activities such as monitoring symptoms and weight daily, managing changes in symptoms, diet and fluid restrictions, engaging in daily exercise to prevent complications and rehabilitation of chronic patients. ${ }^{9}$ Previous research results showed that HF patients' nonadherence to self-care behaviors is still a major challenge, which leads to exacerbation of symptoms, complications, repeated visits to specialist, and unwanted readmission. ${ }^{10}$ Therefore, HF has the highest rate of readmission. Readmission rate due to HF, 30 to 60 days after discharge, has been reported to be $30 \%{ }^{6,11}$

Although education during hospitalization and at the time of discharge is considered as the first essential step, it is inadequate, and patients require self-care behavior support and follow-ups. ${ }^{12}$ Different methods have been proposed for patients' follow-up and providing care after discharge. However, due to the geographical distribution of the patients, long travel distances, required time, lack of resources, and costs, distant patient's education and remote monitoring (tele-monitoring) are essential to provide postdischarge support for patients with HF. ${ }^{13}$ Tele-monitoring or remote monitoring could be effective to actively engage chronic patients to increase their self-care and improve their health. An overview of systematic reviews by Bashi et al showed that tele-monitoring has beneficial effects on clinical outcomes of HF, including a reduction in mortality, HF-related hospitalization, all causes of hospitalization, and an improvement in quality of life (QOL). ${ }^{13}$

Remote patient monitoring makes use of information and communication technologies for remote transfer of accurate and on-time information for determining any deterioration and disease-related complications and to avoid unnecessary physician's visit or emergency admissions. This would allow providing diagnostic, therapeutic, counseling, and educational interventions specifically tailored for each individual patient to prevent disease exacerbations and complications and the need for hospitalization. Audio, video, and other communicational technologies could be adopted through tele-monitoring to remotely monitor, support, and educate the patients. ${ }^{14,15}$ These technologies could be a telephone, computer, remote monitoring tools, internet, video conference, educational packages, audio file, and so on. ${ }^{16}$ Communicational technologies are potential to provide services such as education and counseling to patients with HF remotely. ${ }^{17}$
Using these technologies would help health care professionals to access sufficient and updated information about patients and thus allow safe triage in assessing follow-up care and needs. This will improve health care services productivity and reduce costs. ${ }^{18}$ The use of tele-monitoring increases the accessibility of home-based follow-up with clinical expertise, supervision, and coaching that have traditionally been limited to hospital-based practices. Improving access to health-care services in the remote area, especially to the communities living in rural areas, saves patients' traveling time and cost. Furthermore, treatment can be provided on time, and therefore improving QOL of individuals who reside in remote areas. ${ }^{18}$

Previous studies have mostly focused on educational interventions that were predeveloped contents based on guidelines. $^{19-21}$ However, in this study, we developed a majority of the educational instructions based on the patient's educational needs at the time of extracting patients' tele-monitoring. Also, previous systematic reviews have emphasized on performing tele-monitoring in environments with different socioeconomic status. ${ }^{22,23}$ To the best of our knowledge, no study has been conducted in Iran to examine the tele-monitoring interventions. Hence, the aim of this study was to assess the effects of monitoring through telephone (tele-monitoring) on self-care behaviors and readmission of patients with HF after discharge.

\section{Methods}

This study was a randomized clinical trial with a pretestposttest design. Study population included HF patients hospitalized at the cardiac intensive care units of the Grand Hospital of Dezful in 2016. The inclusion criteria were diagnosis of HF with the New York Heart Association (NYHA) functional classes II and III, ${ }^{24}$ age 45 years or older, ability to communicate in Farsi language, and access to a landline or mobile phone. The exclusion criteria were patients diagnosed with congenital heart disease, hearing impairments, major disability and limitation for self-care, mental illness, Alzheimer's, hemiplegia, paraplegia, and/or organ failure.

Using the OpenEpi software, the sample size was estimated to compare the means of two independent groups with a $95 \%$ confidence level and a $90 \%$ statistical power. Based on a similar study, ${ }^{25,26}$ the standard deviation was considered as 5.59 for the control group and 6.5 for the intervention group. For it to be considered effective intervention, it should be able to reduce the score of self-care behaviors by at least 5 points. The sample size was estimated to be 32 for each group. Considering a $20 \%$ attrition, the final sample size for each group was considered as 40 .

Sampling method used in this study was consecutive sampling, meaning that the researcher had contact with the cardiac intensive care unit of the hospital every day, and eligible HF patients who were willing to participate were enrolled in the study following a written informed consent.

Eligible participants were assigned into two groups of intervention and control using the randomized block method with a fixed-size four-piece block. Random sequence 
generation was performed using Research Randomizer (randomizer.org), and allocations were hidden using dark envelopes, which implies that a number from 1 to 80 from the intervention and control groups generated through random sequence was sealed in the envelope. After the assessment of eligible patients based on the study's inclusion and exclusion criteria and obtaining informed consent, patients were asked to open the randomization envelopes to determine their group.

Data gathering tools for this study were three questionnaires. A demographic characteristics form, which contained 18 questions about age, gender, marital status, patient's educational level, spouse's educational level, job, religion, educational level of the eldest child living with the patient, place of residence, duration of the disease, date of admission, allergy history, underlying diseases, living status (alone, with family, at a nursing house), unhealthy eating habits, and the use of accessories (glasses, cane, etc.).

To evaluate patients' self-care behaviors, the Farsi version of the European $\mathrm{HF}$ self-care behavior questionnaire designed by Jaarsma et al in 2003 was used. The questionnaire comprised 12 questions, and each question was scored based on a 5-point Likert scale, which varies from "that is completely true" with a score of 1 to indicate complete compliance to the appropriate behavior to "that is completely not true" with a score of 5 to indicate noncompliance. The total score varied from 12 to 60 , with lower scores indicating better self-care. This means that scores of 12 to 28 indicated high self-care, 29 to 44 indicated medium selfcare, and 45 to 60 indicated poor self-care.

Validity of the Iranian version of the HF self-care behavior questionnaire has been evaluated in a study, using content validity method and this questionnaire has been used in different studies in Iran. The reliability of the HF self-care behavior questionnaire was calculated as 0.68 using Cronbach's $\alpha$ method. ${ }^{27}$ In this study, the reliability of the questionnaire was evaluated using the test-retest method on 20 samples that were not enrolled in the study 2 weeks before the start of the intervention, and its intraclass correlation was calculated as 0.85 ; this indicated that the questionnaire had a desirable level of reliability.

The third questionnaire was the reporting form for the number of readmissions during the follow-up period. If the patient had readmission, the accuracy of the information was checked through hospital records.

For the eligible participants, HF self-care behavior questionnaire and demographic characteristics form were completed at the hospital prior to commencing the intervention. Then patients' educational needs have been assessed prior to intervention and educational needs were followed-up during the study. Participants of the control group were discharged according to the usual care routine, and education was provided by the nurse at the time of discharge. After discharge from the hospital, participants in the intervention group were followed up using tele-monitoring through phone, lasting for 2 months ( 8 weeks) for each patient. The educational needs of patients were evaluated before and during the follow-up. There was a specific training session for the nurses who performed the intervention. Nurses also used a written consultation protocol, which was reviewed by the research committee.

During the first month, two 20-minute phone calls were made weekly that could vary based on the patients' needs and educational questions; in the second month, calls were made once a week. Educational contents were developed based on the needs of the participants and the HF self-care behavior questionnaire using the literature review and evidence-based sources. Prior to conducting the intervention, the validity of the educational instructions was approved by the expert panel in this field. In this study, intervention included evaluating patient's self-care status, providing necessary recommendations and education for performing self-care behaviors, follow-up, and reevaluation. Education was provided interactively and mostly based on the patients' conditions. Posttest was conducted for the participants of both groups through phone calls 4 weeks after the intervention. At this time, history of readmission due to $\mathrm{HF}$ was asked and recorded. During the final phone call, the posttest and self-care education were provided for the control group exclusively and explained based on patients' needs.

During participant recruitment, the goals and process of the study were completely explained to the participants and they were assured that their information would remain confidential. Then consent forms were signed by participants.

Data were analyzed using descriptive statistics that include frequency table, central tendency and dispersion, chi-square test, Fisher's exact test, independent $t$-test, and analysis of covariance (ANCOVA). For comparing demographic and disease characteristics, and readmission between groups, chi-square and Fisher's exact tests were used. To identify the normal distribution of self-care behavior scores, the KolmogorovSmirnov test was used, and the results indicated that the scores of this variable before and after the intervention were normally distributed. Independent $t$-test was used for comparing the mean score of self-care behaviors before and after the intervention in the groups. Furthermore, ANCOVA was used to compare the scores of self-care behaviors after the intervention with controlled scores before intervention.

\section{Results}

According to - Table 1, demographic and disease characteristics data for the participants $(N=80)$ in the pretest stage showed that the control and the intervention groups had no significant difference regarding their demographic and disease characteristics including age, gender, marital status, educational level, child's educational level, place of residence, duration of the disease, lifestyle, disease history, having any allergies, unhealthy eating behaviors, and using accessories. Therefore, according to the chi-square test, there were no significant differences between the intervention and control groups in the baseline. Of 80 participants recruited and randomized to either the intervention or control group, 12 participants were lost to follow-up ( 5 from the intervention group and 7 from the control group). Hence, data analysis was performed on the outcomes of 35 participants 
Table 1 Demographic characteristics and disease information research samples

\begin{tabular}{|c|c|c|c|c|}
\hline Variable & & $\begin{array}{l}\text { Intervention number } \\
\text { (percent) }\end{array}$ & $\begin{array}{l}\text { Control number } \\
\text { (percent) }\end{array}$ & $p$-Value \\
\hline \multirow[t]{3}{*}{ Age } & $45-50$ & $15(42.9)$ & $14(42.4)$ & \multirow[t]{3}{*}{$0.73^{a}$} \\
\hline & $50-60$ & $8(22.9)$ & $10(30.3)$ & \\
\hline & $60-70$ & $12(34.3)$ & $9(27.3)$ & \\
\hline \multirow[t]{2}{*}{ Gender } & Male & $21(60)$ & $20(60.6)$ & \multirow[t]{2}{*}{$0.57^{\mathrm{b}}$} \\
\hline & Female & $14(40)$ & $13(39.4)$ & \\
\hline \multirow[t]{5}{*}{ Highest educational qualification } & No formal education & $18(51.4)$ & $13(39.4)$ & \multirow[t]{5}{*}{$0.65^{\mathrm{a}}$} \\
\hline & Primary school & $8(22.9)$ & $11(33.3)$ & \\
\hline & Middle school & $3(8.6)$ & $2(6.1)$ & \\
\hline & High school & $6(17.1)$ & $6(18.2)$ & \\
\hline & Academic degree & 0 & $1(3)$ & \\
\hline \multirow[t]{4}{*}{ Employment status } & Employee & $2(5.7)$ & $1(3)$ & \multirow[t]{4}{*}{$0.93^{\mathrm{a}}$} \\
\hline & Unemployed & $9(25.8)$ & $7(21.2)$ & \\
\hline & Housewife & $16(45.7)$ & $15(45.5)$ & \\
\hline & Retired & $8(22.9)$ & $10(30.3)$ & \\
\hline \multirow{2}{*}{$\begin{array}{l}\text { Geographic } \\
\text { residential zone }\end{array}$} & City & $32(91.4)$ & $28(84.8)$ & \multirow[t]{2}{*}{$0.28^{\mathrm{b}}$} \\
\hline & Village & $3(8.6)$ & $5(15.2)$ & \\
\hline \multirow[t]{2}{*}{ HF duration } & Less than a year & $14(40)$ & $16(48.5)$ & \multirow[t]{2}{*}{$0.50^{\mathrm{b}}$} \\
\hline & More than a year & $21(60)$ & $17(51.5)$ & \\
\hline \multirow[t]{3}{*}{ Living arrangement } & Alone & $2(5.7)$ & $2(6.1)$ & \multirow[t]{3}{*}{$0.66^{\mathrm{a}}$} \\
\hline & With family & $33(94.3)$ & $30(90.9)$ & \\
\hline & Nursing Home & 0 & $1(3)$ & \\
\hline \multirow[t]{2}{*}{ History of the other disease } & Yes & $27(77.1)$ & $28(84.8)$ & \multirow[t]{2}{*}{$0.54^{\mathrm{b}}$} \\
\hline & No & $8(22.9)$ & $5(15.2)$ & \\
\hline \multirow[t]{2}{*}{ Allergy } & Yes & $27(77.1)$ & $28(84.5)$ & \multirow[t]{2}{*}{$0.54^{\mathrm{b}}$} \\
\hline & No & $8(22.9)$ & $5(15.2)$ & \\
\hline \multirow[t]{2}{*}{ Living aids equipment } & Uses & $15(42.9)$ & $16(48.5)$ & \multirow[t]{2}{*}{$0.82^{\mathrm{b}}$} \\
\hline & Not use & $20(57.1)$ & $7(21.2)$ & \\
\hline \multirow[t]{2}{*}{ Unhealthy food habits } & Yes & $4(11.4)$ & $7(21.2)$ & \multirow[t]{2}{*}{$0.33^{b}$} \\
\hline & No & $31(88.6)$ & $26(78.8)$ & \\
\hline
\end{tabular}

Abbreviation: HF, heart failure.

${ }^{\mathrm{a}}$ Chi-square test.

${ }^{\mathrm{b}}$ Fisher's exact test.

in the intervention group and 33 participants in the control group (-Fig. 1).

Comparing the pretest scores of self-care behaviors of HF patients between the control and intervention groups using independent $t$-test showed a significant difference $(p=0.045)$. One month after the intervention, the mean score of self-care behaviors was significantly improved in the intervention group compared with the control group $(p<0.001)$. Also, results of ANCOVA showed that the difference between both groups after the intervention was significant $(p<0.001)$ ( - Table 2 ).

Comparing the rate of readmission between both groups after the intervention revealed that $20 \%$ in the intervention group and $42.2 \%$ in the control group were readmitted after the intervention, although the percentage of readmission was higher in the control group compared with the intervention group. Fisher's exact test showed that the intervention was unsuccessful in causing a statistically significant difference between groups regarding the rate of readmission during a period of 3 months (-Table 3).

\section{Discussion}

This study examined the effect of tele-monitoring intervention on the self-care and readmission rates of patients with HF. Results showed that although there was no statistically significant difference in the mean score of patients' self-care 


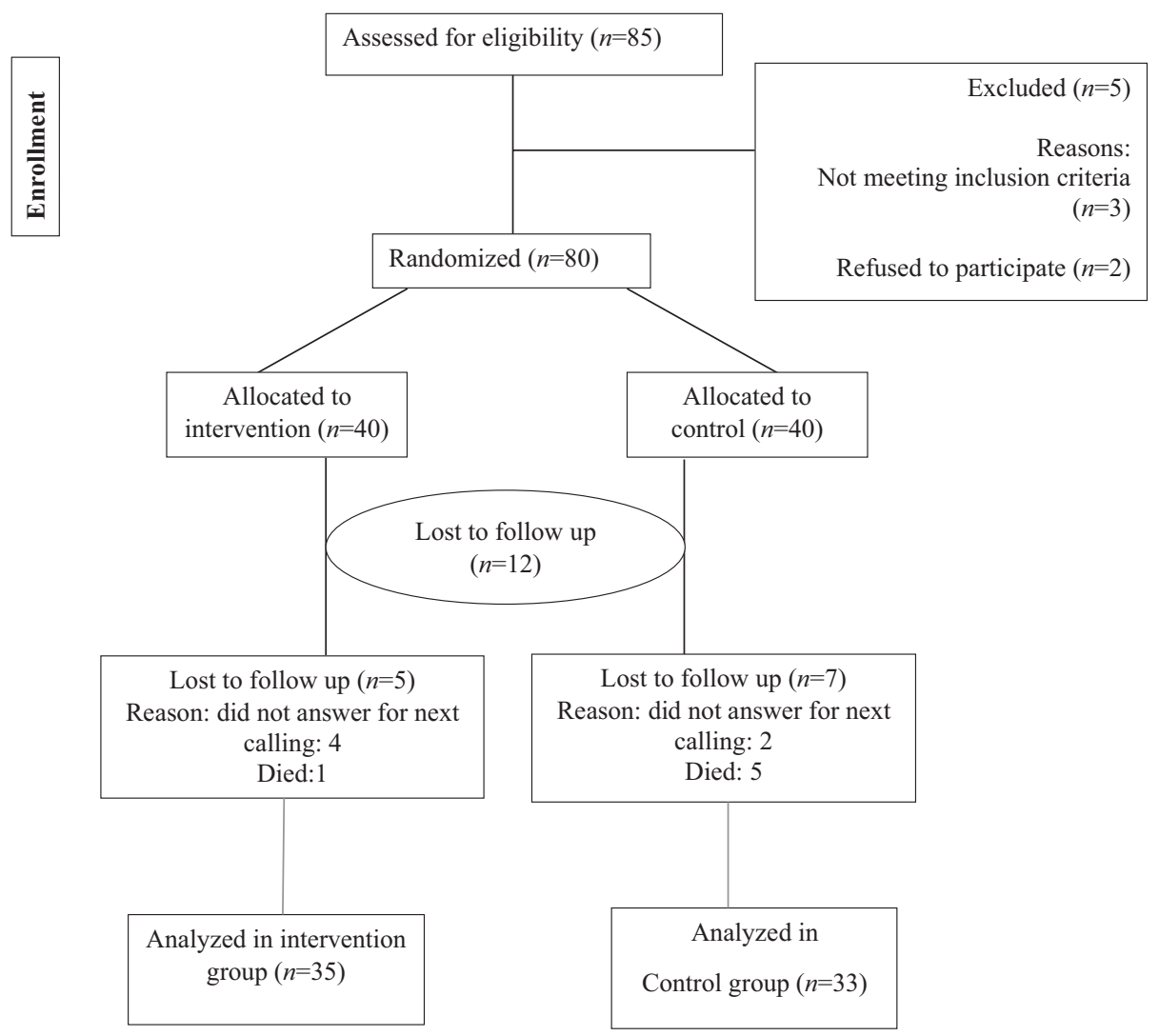

Fig. 1 The study process (consort flowchart).

Table 2 Primary outcome: change in self-care behavior score from baseline (pretest) to postintervention (posttest) self-care behaviors by the studied groups in Iran

\begin{tabular}{|c|c|c|c|c|c|c|}
\hline $\begin{array}{l}\text { Primary } \\
\text { outcome }\end{array}$ & \multicolumn{2}{|l|}{ Intervention group } & \multicolumn{2}{|l|}{ Control group } & $\begin{array}{l}\text { Mean difference } \\
(95 \% \mathrm{Cl})\end{array}$ & $\begin{array}{l}p \text {-Value } \\
\text { ANCOVA }\end{array}$ \\
\hline \multirow[t]{3}{*}{$\begin{array}{l}\text { Self-care } \\
\text { behavior }\end{array}$} & $\begin{array}{l}\text { Pretest Mean (SD) } \\
N=40\end{array}$ & $37.52 \pm 5.24$ & $\begin{array}{l}\text { Pretest Mean (SD) } \\
N=40\end{array}$ & $39.75 \pm 4.51$ & $\begin{array}{l}2.22 \\
(0.047-4.40) \\
p=0.045^{a}\end{array}$ & - \\
\hline & $\begin{array}{l}\text { Posttest Mean (SD) } \\
N=35\end{array}$ & $16.28 \pm 2.49$ & $\begin{array}{l}\text { Posttest Mean (SD) } \\
N=33\end{array}$ & $37.57 \pm 4.65$ & $\begin{array}{l}21.29 \\
(19.45-23.12) \\
p<0.001^{\mathrm{a}}\end{array}$ & $p<0.001^{b}$ \\
\hline & $\begin{array}{l}\text { Prepost difference } \\
\text { Mean }(95 \% \mathrm{Cl}) \\
p \text {-Value }\end{array}$ & $\begin{array}{l}21.08(19.37-22.7) \\
p<0.001\end{array}$ & $\begin{array}{l}\text { Prepost difference } \\
\text { Mean }(95 \% \mathrm{Cl}) \\
p \text {-Value } \mathrm{e}^{\mathrm{c}}\end{array}$ & $\begin{array}{l}2.03 \\
(1.04 \text { to } 3.01) \\
p<0.001\end{array}$ & & \\
\hline
\end{tabular}

Abbreviations: ANCOVA, analysis of covariance; $\mathrm{Cl}$, confidence interval; SD, standard deviation.

andependent $t$-test.

bANCOVA.

'Dependent $t$-test.

Table 3 Readmission rate outcomes after intervention according to the study groups in Iran in 2016

\begin{tabular}{|l|l|l|l|l|l|}
\hline \multirow{2}{*}{ Secondary outcome } & \multicolumn{2}{|l|}{ Intervention } & \multicolumn{2}{l|}{ Control } & \multirow{2}{*}{ Fisher's exact test } \\
\cline { 2 - 5 } & Yes, $N(\%)$ & No, $N(\%)$ & Yes, $N(\%)$ & No, $N(\%)$ & \\
\hline Readmission rate & $7(20)$ & $28(80)$ & $14(42.4)$ & $19(57.6)$ & $p=0.06$ \\
\hline
\end{tabular}

behavior between the intervention and control groups at baseline, the score of self-care behavior was significantly greater in the intervention group at 12-week follow-up in comparison with control group.
In a qualitative study, Riley et al examined the extent to which tele-monitoring in patients with HF enables them to take care of themselves. Most patients used daily telemonitoring and developed self-care skills in HF monitoring. 
Over the 6-month period, such skills were developed. ${ }^{28}$ The results of this study to improve self-care behaviors in patients with HF are consistent with the results of this study.

Jaana et al used tele-monitoring leverage technology for the follow-up of patients with HF. They reported that there was a significant improvement in patients' confidence in their ability to evaluate their symptoms, address them, and evaluate the effectiveness of the measures taken to address these symptoms. Yet, patients performed less self-care maintenance activities, and the capability of involvement in the decision-making related to their condition decreased. ${ }^{29}$ Despite the increasing confidence of patients in identifying and evaluating their own symptoms, self-care behaviors have been reduced. The reasons for this can be a small sample size (23 patients) and a lack of control group.

Another result of this study revealed that the intervention could not decrease the rate of readmission over a period of 3 months. Chaudhry et al examined the effect of telemonitoring in 1,653 patients with HF during 180 days, and their results showed that in an optimized environment, telemonitoring had no superiority over routine cares for recently hospitalized patients and it could not decrease the rate of readmission and mortality in comparison to routine care. ${ }^{30}$ In line with this study, the result of the aforementioned study is the lack of impact of tele-monitoring on the hospitalization rate of patients with $\mathrm{HF}$.

Similar results were also reported in an interventional study conducted by Ong et al in six academic medical centers in California, which assessed the effect of tele-monitoring for HF patients after discharge on the rate of hospitalization. The results showed that tele-monitoring improved patients' QOL during a 180-day period. However, it could not decrease the rate of readmission during 30 days and the rate of mortality during 180 days. $^{31}$

In another study, Bento and Brofman showed that the provision of remote nursing consultation through phone calls reduced the rate of readmission among HF patients. ${ }^{32}$ In their study, the sample size was 40 and consisted mainly of relatively young men with ischemic diseases; therefore, so their results should not necessarily be the same as our results in the HF population.

A systematic review by Tice in 2011, which evaluated the effect of tele-monitoring in HF patients, also indicated that educating patients and their families in addition to adequate follow-ups would decrease the rate of readmission and mortality. ${ }^{23}$ Therefore, this systematic review also reported results similar to that of Bento and Brofman.

A study conducted by Delaney et al on the efficacy of a tele-monitoring and self-care education intervention showed a reduction in hospitalization and improvement in QOL and patient's knowledge of HF following 90 days of home care postdischarge. ${ }^{33}$ The results of this study confirm the decrease in the readmission rate after 90 days of telemonitoring, which is contrary to the results of this study. The reasons for this result may be the selection of patients in NYHA class III; the sample size in this study was 100 and comprised mostly white.
A study by Chiu and Wong titled "Effects of 8 weeks sustained follow-up after a nurse consultation on hypertension: A randomised trial" was conducted in Hong Kong in 2010. Phone follow-up by the nurses was reported to be very valuable in patients' self-management plan. ${ }^{34}$ The results of the aforementioned study on the impact of tele-monitoring on the improvement of disease management are in line with this study.

Also, the systematic review and meta-analysis study of Tse et al revealed that both tele-monitoring and hemodynamic monitoring are equally effective approaches to reducing hospitalization rates in HF. Tele-monitoring should be used more widely since it is less invasive than hemodynamic monitoring and may be more cost-effective. ${ }^{20}$ The study provides results for the positive effect of tele-monitoring on reducing the hospitalization rate, which is contrary to the results of this study. One of the reasons for this conclusion, which was mentioned by the researchers in the limitations of this study, is the low number of studies on the impact of telemonitoring on the hospitalization rate. Perhaps, only studies with positive results in readmission are reported in the journals and analyzed in this meta-analysis.

\section{Study Limitations}

The limitations of this study include small sample size, not considering patients' HF knowledge in designing and executing the intervention, the effects of awareness raising and selfesteem enhancement on self-assessment of patients, and the short period of follow-up, which could be the cause for not achieving a statistical significant difference in the rate of $\mathrm{HF}$ readmission. Therefore, we recommend that future studies consider longer periods of follow-up (6-9 months) and recruit a larger sample. Furthermore, to provide education compatible with patients HF knowledge, it is recommended to develop educational instructions based on the patients' disease knowledge.

\section{Conclusion}

The results of this study showed that tele-monitoring might improve self-care behaviors in patients with HF. However, it did not decrease the rate of readmissions. Tele-monitoring is essential to intensify education and improve HF self-care in developing countries such as Iran. Its role should be encouraged in remote areas with limited access to health care professionals and its potential to reduce possible causes of mortality and hospitalization for HF.

\section{Clinical Relevance Statement}

Although HF patients receive education and self-management support during hospitalization, they require long-term support to improve their self-management skills and achieve desired behavioral change. Tele-monitoring is one of the methods that is used for continuity of care after discharge. By providing empirical evidence, this study encourages nurses to pursue this program to improve patients' self-care. 


\section{Multiple Choice Questions}

1. In chronic disease self-management, the best therapeutic results would be achieved when?

a. A patient is actively involved in self-care.

b. The standard hospital care is delivered to a patient.

c. Nurses have sufficient and up to date knowledge.

d. having regular visits to specialist and readmission.

Correct Answer: The correct answer is option a. Due to the chronic nature of this disease, most of the treatments are focused on managing the process of the disease and self-care. ${ }^{9}$ Hence, the best therapeutic results would be achieved when the patient is actively involved in selfmanagement of his/her condition. So option a is correct. Option b is not correct because the standard hospital care should be delivered to all patients, and based on the nature of $\mathrm{HF}$, it is not enough for the patient after discharge. In addition, option $c$ is not correct because the patient needs to have enough knowledge and motivation to monitor and manage symptoms and complications of HF. Option d is incorrect because the repeated visits to specialist and readmission rate indicate nonadherence to self-care behaviors.

2. What was the method of randomization of this study?
a. Quasi-randomization.
b. Simple randomization.
c. Block randomization.
d. Stratified block randomization.

Correct Answer: The correct answer is option c. Randomization reduces opportunities for bias and confounding in experimental designs. Quasi-random allocation is a method of allocating participants to different forms of care that is not truly random, for example, allocation by date of birth, day of the week, medical record number, month of the year, or the order in which participants are included in the study (alternation). So option a is incorrect. Option b is incorrect because simple randomization is a method analogous to tossing a coin to assign patients to treatment groups. It is usually implemented by using a computer that generates a list of random numbers. Noteworthy, random allocation can be made in blocks to keep the sizes of treatment groups similar. To do this, you must specify a sample size that is divisible by the block size you choose. An advantage of small block sizes is that treatment group sizes are very similar. A disadvantage of small block sizes is that it is possible to guess some allocations, thus reducing concealment in the randomization. Therefore, option c is correct. Lastly, option $d$ is incorrect because stratified randomization is used to ensure that equal number of participants with a characteristic thought to affect prognosis or response to the intervention will be allocated to each comparison group. In any randomized trial, it is desirable that the comparison groups should be as similar as possible as regards those characteristics that might influence the response to the intervention. For example, in a trial of women with breast cancer, it may be important to have a similar number of premenopausal and postmenopausal women in each comparison group. Stratified randomization could be used to allocate equal number of pre- and postmenopausal women to each treatment group.

\section{Protection of Human and Animal Subjects}

This study was performed in compliance with the World Medical Association Declaration of Helsinki on Ethical Principles for Medical Research Involving Human Subjects and was reviewed by the Tehran University of Medical Sciences' Ethics Committee with approval ID: IR.TUMS. VCR.REC.1395.938.

\section{Funding}

This study was part of an MSc thesis supported by the Tehran University of Medical Sciences (Grant No: 33181).

Conflict of Interest

None declared.

\section{Acknowledgments}

We would like to express our special thanks to all patients who participated in this study. Moreover, we are grateful to Dezful Grand Hospital for supporting the study, and, finally, we are grateful to Abdul-Razak Doat, PhD Student, International Campus, School of Nursing \& Midwifery, Tehran University of Medical Sciences, for editing this article.

\section{References}

1 Brunner LS, Smeltzer SCC, Bare BG, Hinkle JL, Cheever KH. Brunner \& Suddarth's Textbook of Medical-Surgical Nursing. Philadelphia, PA: Lippincott Williams \& Wilkins; 2010:257-281

2 McMurray JJ, Adamopoulos S, Anker SD, et al; Task Force for the Diagnosis and Treatment of Acute and Chronic Heart Failure 2012 of the European Society of Cardiology; ESC Committee for Practice Guidelines. ESC guidelines for the diagnosis and treatment of acute and chronic heart failure 2012: the Task Force for the Diagnosis and Treatment of Acute and Chronic Heart Failure 2012 of the European Society of Cardiology. Developed in collaboration with the Heart Failure Association (HFA) of the ESC. Eur J Heart Fail 2012;14(08):803-869

3 Savarese G, Lund LH. Global public health burden of heart failure. Card Fail Rev 2017;3(01):7-11

4 Rajadurai J, Tse H-F, Wang C-H, Yang N-I, Zhou J, Sim D. Understanding the epidemiology of heart failure to improve management practices: an Asia-Pacific perspective. J Card Fail 2017;23 (04):327-339

5 Givi M, Shafie D, Nouri F, Garakyaraghi M, Yadegarfar G, Sarrafzadegan N. Survival rate and predictors of mortality in patients hospitalised with heart failure: a cohort study on the data of Persian registry of cardiovascular disease (PROVE). Postgrad Med J 2018;94(1112):318-324

6 Ahmadi A, Soori H, Mobasheri M, Etemad K, Khaledifar A. Heart failure, the outcomes, predictive and related factors in Iran. Majallah-i Danishgah-i Ulum-i Pizishki-i Mazandaran 2014;24(118): $180-188$

7 Lesyuk W, Kriza C, Kolominsky-Rabas P. Cost-of-illness studies in heart failure: a systematic review 2004-2016. BMC Cardiovasc Disord 2018;18(01):74 
8 Ditewig JB, Blok H, Havers J, van Veenendaal H. Effectiveness of self-management interventions on mortality, hospital readmissions, chronic heart failure hospitalization rate and quality of life in patients with chronic heart failure: a systematic review. Patient Educ Couns 2010;78(03):297-315

9 Buck HG, Harkness K, Wion R, et al. Caregivers' contributions to heart failure self-care: a systematic review. Eur J Cardiovasc Nurs 2015;14(01):79-89

10 Jaarsma T, Strömberg A, Mårtensson J, Dracup K. Development and testing of the European Heart Failure Self-Care Behaviour Scale. Eur J Heart Fail 2003;5(03):363-370

11 Jackson JD, Cotton SE, Bruce Wirta S, et al. Burden of heart failure on patients from China: results from a cross-sectional survey. Drug Des Devel Ther 2018;12:1659-1668

12 Shojaee A, Nehrir B, Naderi N, Zareiyan A. Effect of patient education and telephone follow up by the nurse on the level of hope in patients suffering from heart failure. 2013. J Nurs Educ 2013;3(02):16-26

13 Bashi N, Karunanithi M, Fatehi F, Ding H, Walters D. Remote monitoring of patients with heart failure: an overview of systematic reviews. J Med Internet Res 2017;19(01):e18

14 Paré G, Moqadem K, Pineau G, St-Hilaire C. Clinical effects of home telemonitoring in the context of diabetes, asthma, heart failure and hypertension: a systematic review. J Med Internet Res 2010; 12(02):e21

15 Paré G, Jaana M, Sicotte C. Systematic review of home telemonitoring for chronic diseases: the evidence base. J Am Med Inform Assoc 2007;14(03):269-277

16 McGonigle D, Mastrian K. Nursing Informatics and the Foundation of Knowledge. Burlington, MA: Jones \& Bartlett Publishers; 2014

17 Khodadadi A, Sayadi A, Smaeli H. Evolution of Knowledge of the principles of self care in acute coronary syndrome patients admitted to Aliebn Abitaleb Rafsanjan university hospital during 2009. Community Health Journal. 2010;5(01):8-16(Persian)

18 Passyavula SK. Telemedicine, telenursing \& tele education - a revolution multi innovation in current nursing scenario. International Journal Of Medical And Health Research. 2016;2(05): 31-32

19 Boroumand S, Moeini M. The effect of a text message and telephone follow-up program on cardiac self-efficacy of patients with coronary artery disease: a randomized controlled trial. Iran J Nurs Midwifery Res 2016;21(02):171-176

20 Tse G, Chan C, Gong M, et al; International Health Informatics Study (IHIS) Network. Telemonitoring and hemodynamic monitoring to reduce hospitalization rates in heart failure: a systematic review and meta-analysis of randomized controlled trials and real-world studies. J Geriatr Cardiol 2018;15(04):298

21 Hayakawa M, Uchimura Y, Omae K, Waki K, Fujita H, Ohe K. A smartphone-based medication self-management system with real-time medication monitoring. Appl Clin Inform 2013;4(01): 37-52

22 Clarke M, Shah A, Sharma U. Systematic review of studies on telemonitoring of patients with congestive heart failure: a metaanalysis. J Telemed Telecare 2011;17(01):7-14

23 Tice JA, ed. Home Telemonitoring for the Management of Heart Failure. San Francisco, CA: California Technology Assessment Forum; 2011

24 Tripoliti EE, Papadopoulos TG, Karanasiou GS, et al , eds. Estimation of New York Heart Association Class in Heart Failure Patients Based on Machine Learning Techniques. Presented in the 2017 IEEE EMBS International Conference on Biomedical \& Health Informatics, 2017;16(19)

25 Heidari M, Sarvandian S, Moradbeigi K, Akbari Nassaji N, Vafaizadeh M. Comparing the effect of telenursing and education without follow-up in the caregivers of heart failure patients on the self-care behavior and clinical status of heart failure patients. J Hayat 2017;23(01):44-58

26 Baghiani Moghadam MH, Taheri G, Fallah Zadeh H, Parsa M. The effect of instructional designed SMS based on Health Belief Model (HBM) on adoption of self-care behavior of patients with type II diabetes. Modern Care J 2014;11(01):10-18

27 Jaarsma T, Strömberg A, Ben Gal T, et al. Comparison of self-care behaviors of heart failure patients in 15 countries worldwide. Patient Educ Couns 2013;92(01):114-120

28 Riley JP, Gabe JP, Cowie MR. Does telemonitoring in heart failure empower patients for self-care? A qualitative study. J Clin Nurs 2013;22(17-18):2444-2455

29 Jaana M, Sherrard H, Paré G. A prospective evaluation of telemonitoring use by seniors with chronic heart failure: adoption, self-care, and empowerment. Health Informatics J 2018 Doi: $10.1177 / 1460458218799458$

30 Chaudhry SI, Mattera JA, Curtis JP, et al. Telemonitoring in patients with heart failure. N Engl J Med 2010;363(24):2301-2309

31 Ong MK, Romano PS, Edgington S, et al; Better Effectiveness After Transition-Heart Failure (BEAT-HF) Research Group. Effectiveness of remote patient monitoring after discharge of hospitalized patients with heart failure: the Better Effectiveness after Transition - Heart Failure (BEAT-HF) Randomized Clinical Trial. JAMA Intern Med 2016;176(03):310-318

32 Bento VFR, Brofman PRS. Impact of the nursing consultation on the frequency of hospitalizations in patients with heart failure in Curitiba, Parana State. Arq Bras Cardiol 2009;92(06):490-496

33 Delaney C, Apostolidis B, Bartos S, Morrison H, Smith L, Fortinsky R. A randomized trial of tele-monitoring and self-care education in heart failure patients following home care discharge. Home Health Care Manage Pract 2013;25(05):187-195

34 Chiu CW, Wong FK. Effects of 8 weeks sustained follow-up after a nurse consultation on hypertension: a randomised trial. Int J Nurs Stud 2010;47(11):1374-1382 